\title{
La miseria de la
}

degeneración: el materialismo de Buffon y las 'limitaciones' de su transformismo

\section{The misery of degeneration: Buffon's materialism and the 'limitations' of his transformism}

\author{
Gustavo Caponi \\ Pesquisador do CNPq; professor associado \\ do Departamento de Filosofia/ \\ Universidade Federal de Santa Catarina \\ Rua Estéves Jr., 605/1414 \\ 88015-130 - Florianópolis - SC - Brasil \\ gustavocaponi@newsite.com.br
}

Recebido para publicação em março de 2008. Aprovado para publicação em outubro de 2009.
CAPONI, Gustavo. La miseria de la degeneración: el materialismo de Buffon y las 'limitaciones' de su transformismo. História, Ciências, Saúde - Manguinhos, Rio de Janeiro, v.16, n.3, jul.-set. 2009, p.683-703.

\section{Resumen}

En "De la degeneración des animales", de 1766, Buffon sostuvo un 'transformismo limitado' que, doce años después, en Las épocas de la naturaleza, sería complementado por una teoría materialista sobre el origen de la vida que ponía en evidencia que, para el cientista, esa alternativa estaba vedada: las condiciones bajo las cuales los seres vivos desarrollan sus existencias podrían explicar cómo las diferentes especies que componen los distintos géneros de animales se habrían formado a partir de la degeneración de una especie originaria. Pero, la constitución de esas múltiples cepas primigenias sólo podría explicarse por un súbito proceso de generación espontánea. Una limitación inherente al propio sistema de ideas que lo había llevado hasta ese transformismo limitado: la propia teoría de la generación y la reproducción que le servía de base inhibía la posibilidad de su radicalización.

Palabras-claves: Buffon; degeneración; generación; materialismo; transformismo.

\section{Abstract}

In "Of the degeneration of animals" (1766), Buffon espoused a kind of limited transformism. Yet twelve years later, in Epochs of Nature, he supplemented this with a materialist theory on the origin of life that left no room for this alternative: the conditions under which living beings develop could explain how the different species within each animal genus had formed through the degeneration of an originating species. But the formation of these multiple, originating varieties could only be explained by a sudden process of spontaneous generation. A limitation inherent to the very system of ideas that had taken Buffon to limited transformism the underlying theory of generation and reproduction-preempted the possibility of its radicalization.

Keywords: Buffon; degeneration; generation; materialism; reproduction; transformism. 
$\mathrm{E}$ n los escritos de Buffon, el primer atisbo de un pensamiento 'transformista' puede encontrarse en el artículo "El asno" que integraba el cuarto tomo de la Historia natural aparecido en 1753. Allí, después de considerar la posibilidad de que ese animal no fuese otra cosa que un simple caballo 'degenerado' por los efectos del clima y la alimentación, acumulados a lo largo de generaciones, Buffon no sólo formula y afirma, con toda claridad, aquello que, casi ochenta años más tarde, Etienne Geoffroy Saint-Hilaire (1998, p.141) llamaría la 'ley de la unidad de composición orgánica', sino que además también nos dice que la existencia de ese 'diseño primitivo y general' compartido por todos los animales, incluido el hombre, podría hacer pensar que "todos los animales descienden de un único animal que, con el transcurso del tiempo, produjo, tanto degenerando como perfeccionándose, todas las razas de los otros animales"1 (Buffon, 1868, p.35-36).

Sin embargo, y aun sin mediar ningún cuestionamiento a la propia existencia de ese 'diseño común' sobre el cual Buffon (1766, p.28-29) insistirá en su "Nomenclatura de los simios", las conjeturas transformistas son ahí mismo sumariamente descartadas, aduciéndose que "es sabido por revelación que todos los animales participaron igualmente de la gracia de la creación" y que "todas las especies surgieron plenamente formadas de las manos del creador" (Buffon, 1868, p.35). El asno, dirá finalmente Buffon (p.39), "es ... un asno, y no un caballo degenerado"; y "aunque su nobleza sea menos ilustre, ella es tan buena y tan antigua cuanto la del caballo".

Pero, ya en 1761, en el final del artículo sobre los "Animales comunes a los dos continentes", las convicciones fijistas de Buffon parecen menos sólidas. Allí, la inextricable mixtura de notorias diferencias y vagas semejanzas que algunos animales de América guardan con otros del Viejo Continente, lo llevan a pensar en la posibilidad de que los primeros, aun constituyendo en el presente especies diferentes de las encontradas en Europa, África y Asia, no sean otra cosa que formas desnaturadas, por efecto del clima y del aislamiento, de los animales que habitan en esas otras regiones del globo (Buffon, 1761, p.127). Es, con todo, en 1766, en el célebre ensayo "De la degeneración de los animales", que Buffon (1766, p.311-374) se atreverá a asumir, de modo explícito y directo, un cierto 'transformismo limitado' (Rostand, 1932, p.49, 1958, p.602, 1985, p.47) que, doce años después, en Las épocas de la naturaleza (Buffon, 1988), será complementado por una teoría audazmente materialista sobre el origen de la vida.

Esta teoría, sin embargo, lejos de propiciar una radicalización de ese transformismo, ponía en evidencia que, para Buffon, esa alternativa estaba vedada: las condiciones bajo las cuales los seres vivos desarrollan sus existencias, podrían explicar cómo las diferentes especies que componen los distintos géneros de animales se habrían formado a partir de la degeneración de una especie originaria; pero, la constitución de esas múltiples cepas primigenias sólo podría explicarse por un súbito proceso de generación espontánea. Buffon no pudo llegar a concebir el árbol de la vida consagrado por Darwin, ni pudo imaginar el tránsito del infusorio al hombre postulado por Lamarck; y es sobre las razones de esa 
imposibilidad que aquí me habré de preguntar. Aun atreviéndose a conjeturar una explicación puramente materialista para el origen de la vida, y aun habiendo llegado a entrever los perfiles que podría tomar un transformismo radical, Buffon no ensayó ese paso y ni siquiera discutió su posibilidad. Algo le cerraba el camino, algo le impedía esa alternativa; y creo que podré mostrar que el obstáculo residía en el interior del propio sistema de ideas que había llevado a Buffon hasta ese transformismo limitado enunciado en 1766.

Diré, en efecto, que la principal limitación del transformismo buffoniano es interna o constitutiva a la idea de degeneración; y obedece, sobre todo, a la propia teoría de la reproducción que le sirve de base. Ésta hacía posible la degeneración de los animales, pero, al mismo tiempo, limitaba al extremo cualquier invención o novedad morfológica; y era eso lo que impedía el paso hacía una radicalización del transformismo. La idea que, aparentemente, casi dejó a Buffon al filo del evolucionismo decimonónico, se basaba en una hipótesis que no permitía franquear el umbral que, por distintas vías y con suerte diversa, Lamarck y Darwin habrían de transponer. Pero Buffon no ignoraba esa limitación; y fue precisamente para remedarla que propuso la teoría sobre el origen de la vida presentada en Las épocas de la naturaleza.

\section{Generación y degeneración}

Buffon (1749a, p.44) siempre insistió: "existe en la naturaleza una infinidad de partes orgánicas vivas" de las que "los seres organizados se componen" y cuya "producción nada le cuesta a la Naturaleza, porque su existencia es constante e invariable": cuando un ser vivo muere ellas no son destruidas sino simplemente separadas (Buffon, 2007g, p.571; 2007c, p.747); y son precisamente esas partículas o moléculas, "primitivas e incorruptibles" (Buffon, 1749a, p.24), las que sirven como nutrientes de todos los seres vivos: "la materia orgánica que animales y vegetales asimilan a su sustancia es una materia orgánica que es de su misma naturaleza y, por eso, ellos pueden aumentar en masa y volumen sin cambiar de forma y sin alterar la calidad de su materia" (p.44). Pero para que eso sea posible, nos dice Buffon (p.41), también es preciso pensar que:

El cuerpo de un animal es una especie de molde interior, en el que la materia que sirve a su crecimiento se modela y se asimila al todo, de manera que, sin que ocurra ningún cambio en el orden y la proporción de las partes, de ahí resulte, sin embargo, un aumento en cada parte tomada separadamente; y es ese aumento de volumen que llamamos desarrollo, porque se creyó explicarlo diciendo que, estando el animal formado en pequeño como él es de grande, no seria difícil concebir que las partes se desarrollaban a medida que una materia accesoria venía a aumentar proporcionalmente cada una de ellas. Pero este mismo aumento, este desarrollo, si se quiere tener una idea nítida de él, sólo puede pensarse considerando el cuerpo del animal, e incluso cada una de sus partes que deben desarrollarse, como siendo moldes interiores que sólo reciben la materia accesoria en el orden que resulta de la posición de todas ellas.

Ahora bien, si suponemos "que el cuerpo del animal o del vegetal es un molde interior que posee una forma constante, pero cuya masa y volumen pueden aumentar proporcionalmente, y que el crecimiento, o, si se quiere, el desarrollo del animal o del vegetal ocurre por 
la extensión de ese molde en todas sus direcciones exteriores e interiores" (Buffon, 1749a, p.42-43), no podremos explicar ese proceso sin presuponer que ese molde ya está constituido antes de que el mismo comience (Roger, 1993, p.546); y es eso lo que Buffon hace apelando a una teoría en la cual los gérmenes, o moldes, de los nuevos organismos son considerados como un subproducto del propio proceso de nutrición y crecimiento de sus progenitores (Aréchiga, 1999, p.5). Según tal teoría, cuando la materia nutritiva asimilada por un organismo formado excede el nivel necesario para garantir su propia nutrición y su desarrollo, cosa que en general sólo ocurre en el organismo adulto, "ella es reenviada desde todas las partes del cuerpo hacia uno o varios reservorios bajo la forma de un licor que contiene todas las moléculas análogas al cuerpo del animal y, consecuentemente, todo aquello que es necesario a la reproducción de un pequeño ser enteramente semejante al primero" (Buffon, 1749a, p.422).

Buffon supone, en efecto, que cada parte del organismo 'devuelve' aquellas 'moléculas orgánicas' que no precisa para mantenerse o crecer, pero no las devuelve como las recibió: las devuelve ya modeladas; y esto permite que, una vez juntas en esos reservorios, las mismas, siguiendo su natural impulso a aglomerarse, se puedan amalgamar conforme un orden que reproduce el molde del organismo que las asimiló (Flourens, 1864, p.46).

\footnotetext{
Cada parte del cuerpo reenvía las moléculas orgánicas que ya no puede aceptar"; pero "esas moléculas son absolutamente análogas a cada parte desde las que son reenviadas, porque ellas estaban destinadas a nutrir esa parte; por eso, cuando todas las moléculas reenviadas desde todo el cuerpo se juntan, ellas deben formar un cuerpito parecido al primero, porque cada molécula es parecida a la parte desde la que fue reenviada (Buffon, 1749a, p.425).
}

Es decir, para Buffon, como para los preformacionistas, el desarrollo es simplemente el crecimiento de un germen ya conformado; pero para él "no hay gérmenes preexistentes, ni gérmenes contenidos al infinito los unos dentro de los otros, sino una materia orgánica siempre activa, siempre lista a amoldarse, a asimilarse y a producir seres semejantes a aquellos que la reciben" (p.426). Y es precisamente ese preformacionismo sin preexistencia (Roger, 1993, p.546) lo que le permite explicar la degeneración. Es que, si es todo el organismo el que reproduce su forma en virtud del moldeamiento que cada una de sus partes ejerce sobre las partículas de materia orgánica que compondrán al embrión (Roger, 1989, p.412), entonces, el estado en que esas partes se encuentren en el momento de recibir y devolver esas partículas orgánicas innecesarias para su propia nutrición, también incidirá en los perfiles que ese nuevo organismo venga a adoptar. No siendo otra cosa que el propio organismo engendrante, el 'molde interno' del que habla Buffon no es un arquetipo ajeno e inmune a los avatares del mundo; y eso permite entender que los efectos que el clima, la dieta y el modo de vida puedan ejercer sobre un organismo acaben afectando a su descendencia.

Como tantos otros naturalistas desde Aristóteles en adelante (Gayon, 2006, p.105), Buffon nunca dudó de lo que hoy llamaríamos transmisión de las modificaciones o de los caracteres adquiridos (Rostand, 1932, p.64); y su teoría de la reproducción constituía una explicación razonablemente satisfactoria de ese fenómeno. Ella no sólo permitía explicar el hecho de que "los perros a los que, de generación en generación, se le cortan las orejas y el rabo, transmiten esas faltas, total o parcialmente, a sus descendientes" (Buffon, 1766, 
p.322) sino que también permitía comprender cómo los efectos que el clima y la alimentación ejercen sobre los perfiles de lo viviente eran pasibles de acumularse y acentuarse a lo largo de generaciones sucesivas. Por eso, para entender el mecanismo de la degeneración, y la naturaleza de los cambios que él puede producir, es menester comprender el modo por el cual los factores ambientales y el modo de vida pueden afectar los perfiles de ese organismo individual que serviría de molde para ese nuevo organismo a ser formado; y a este respecto ningún texto de Buffon nos pareció más claro que su artículo sobre el ciervo aparecido en el tomo sexto de la Historia natural. "Lo que hay de más constante, de más inalterable en la Naturaleza - leemos allí -, es el molde de cada especie, tanto en los animales cuanto en los vegetales", y "lo que hay de más variable y corruptible es la sustancia que los compone". Ésta, "en general, parece ser indiferente a recibir tal o cual forma, y pasible de soportar todos los moldeamientos posibles: las moléculas orgánicas, es decir, las partes vivas de esa materia pasan de los vegetales a los animales sin destrucción, sin alteración, y forman indiferentemente la sustancia viviente de la hierba, de la madera, de la carne y del hueso". Se podría decir, por eso, que en los seres vivos "la materia jamás puede prevalecer sobre la forma, y que sea cual sea la especie de alimento que tome un animal, ... ese alimento no podrá cambiar su forma, y no tendrá otro efecto que el de mantener o el de hacer crecer su cuerpo modelándose conforme cada parte del molde interior"; y esto explicaría muy bien el hecho de que "los animales que viven sólo de hierba, que parece ser una sustancia muy diferente de la de su cuerpo, obtengan de esa hierba con que hacer carne y sangre" (Buffon, 2007e, p.722).

Sin embargo, continua Buffon (2007e, p.722-723), si observamos la naturaleza de un modo más atento, "percibiremos que a veces esas moléculas orgánicas no se asimilan perfectamente al molde interior, y que a menudo la materia influye sobre la forma de una manera bastante sensible: el tamaño, por ejemplo, que es uno de los atributos de la forma, varía en cada especie según los diferentes climas; [mientras tanto] la calidad y la cantidad de la carne, que son otros atributos de la forma, varían según los diferentes alimentos". Es decir: "esa materia orgánica que el animal asimila a su cuerpo por la nutrición, no es entonces absolutamente indiferente a recibir tal o cual modificación, ella no está absolutamente despojada de la forma que tenía anteriormente, y retiene algunos caracteres propios de su primer estado"; y, de ese modo, "ella actúa ... por su propia forma sobre la del cuerpo organizado que nutre". Por eso, "aunque esa acción sea casi insensible" e "infinitamente pequeña en comparación a la de la forma que constriñe esa materia nutritiva a asimilarse al molde que la recibe", la misma "debe producir, con el tiempo, efectos muy sensibles".

Esa resistencia activa que la materia ejerce en contra de la hegemonía de la forma, queda perfectamente ilustrada en el caso de los cuernos del ciervo. Este animal, nos dice Buffon (2007e, p.723), "que sólo habita en el bosque, y que vive exclusivamente, por así decir, del propio bosque, porta sobre su cabeza una especie de madera, que no es otra cosa que un residuo de esa alimentación". El castor, mientras tanto, "que habita las aguas, y que se nutre de pescado, posee una cola cubierta de escamas"; y algo semejante ocurre con "la carne de la nutria y de la mayoría de las aves ribereñas". Estos animales, sostiene Buffon, nos proveen "una comida de cuaresma, una especie de carne de pescado". Se puede presumir, por eso: 
Que animales a los cuales se les diese siempre la misma especie de comida, tomarían en bastante poco tiempo un barniz de las cualidades de esa comida, y que, por fuerte que sea la impronta de la Naturaleza, si se continuase siempre a darles la misma alimentación, con el tiempo resultaría una especie de transformación ... contraria a esa Naturaleza. No sería ya el alimento que se asimilaría enteramente a la forma del animal, sino el animal que se asimilaría, en parte, a la forma del alimento, como lo vemos en los cuernos del ciervo y en la cola del castor (p.723).

En cierto modo, parece decir Buffon, "somos lo que comemos"; y esto también permitiría explicar el hecho de que, en general, la influencia del alimento sea mayor, y produzca efectos más notorios "sobre los animales que se nutren de hierbas o de frutos" (Buffon, 1766, p.321). Mientras tanto, los animales "que viven de sus presas varían menos por esa causa que por la influencia del clima; porque la carne es un alimento preparado y ya asimilado a la Naturaleza del animal carnicero que la devora; en cuanto que la hierba, siendo el primer producto de la tierra, posee todas sus propiedades, y transmite inmediatamente las cualidades terrestres al animal que de ella se nutre" (p.321-322). Pero, lamentablemente, en ningún lugar Buffon nos da una explicación de cómo el clima produce esos efectos sobre los perfiles de los seres vivos que sea tan explícita como aquella que nos dio sobre los efectos de la alimentación. Queda claro, sin embargo, que consideraba que el color, el tamaño y el temperamento de los vivientes eran muy sensibles a esa variable (Buffon: 1749b, p.528; 2007d, p.775; 2007b, p.980; 1766, p.329).

Puede inferirse, además, que Buffon tendía a suponer que esa influencia del clima sobre los perfiles de lo viviente también se ejercía por la mediación de la alimentación (Buffon, 1766, p.315). El clima de una región, según nos dice en "Los animales salvajes", afecta más directamente a los vegetales que en allí crecen; y es por la mediación de éstos que ese clima influye sobre las cualidades de los hombres y las bestias carnívoras. "La tierra - leemos allí - hace las plantas, la tierra y las plantas hacen a los animales", y "la tierra, las plantas y los animales hacen al hombre". Por eso, las cualidades físicas y las costumbres "del hombre y de los animales que viven sobre los otros animales como sobre las plantas, dependen, aunque menos inmediatamente, de esas mismas causas" que afectan la vida y el crecimiento de esos seres que los sustentan (Buffon, 2007f, p.705). La alimentación parece ser, al final de cuentas, la variable más decisiva. Como observaba Rostand (1932, p.63) comentando este aspecto del pensamiento de Buffon, al influenciar la forma interior "actúa de una manera más profunda que el clima".

\section{Degeneración, aclimatación y adaptación}

Es también muy posible que Buffon haya pensado que los procesos por medio de los cuales un organismo individual responde para sobreponerse y adecuarse a un cambio de la temperatura ambiente, o de cualquier otra variable atmosférica, podían también afectar, de un modo permanente, algunos aspectos de su constitución y, así, influir también en los rasgos de su descendencia. En este sentido, se podría considerar a Buffon como un precursor de las tesis aclimatacionistas (Osborne, 1994; Caponi, 2007) desarrolladas más tarde por Isidore Geoffroy Saint Hilaire $(1832,1861)$. Debemos cuidarnos, sin embargo, de atribuirle al proceso de degeneración una positividad que Buffon estaba muy lejos de concederle. La 
degeneración no era para él la conquista de la armonía con un nuevo clima: es la simple degradación de la forma originaria que las condiciones de vida producen (Bowler, 1994, p.133).

Buffon no piensa que los animales gocen de ese relativo cosmopolitismo que, en algunos casos, Isidore Geoffroy Saint-Hilaire (1861, p.143) les atribuye. Cada animal, piensa Buffon (1761, p.2), "tiene su país, su patria natural en la cual cada uno es retenido por necesidad física, cada uno es hijo de la tierra que habita, y es en ese sentido que se debe decir que tal o cual animal es originario de tal o cual clima". Es, por lo tanto, a esa patria natural que debemos remitirnos para conocer la forma original de una especie: fuera de ahí, sus perfiles siempre estarán trastocados y su forma adulterada.

La degeneración, podemos decir, nunca es una conquista; ella es siempre una resignación: un 'dejarse estar' que, como siempre, acaba en un 'dejar de ser'. Y ese es, al final de cuentas, la única modalidad de cambio transgeneracional de las formas vivas que Buffon pudo concebir: cualquier perfeccionamiento que pudiésemos entrever en ciertas estructuras no era para él más que una eventual proyección sobre la naturaleza de nuestros puntos de vistas, gustos o intereses. Porque, relativamente a la propia naturaleza, todo cambio producido por las circunstancias, y sobre todo por la domesticación, es siempre una degeneración (Buffon, 1766, p.318); y es por eso que la temática del perfeccionamiento, mencionada en el artículo sobre el asno, casi desaparece por completo en los escritos posteriores de Buffon.

Debemos cuidarnos, por eso, de incurrir en el error de confundir estas tesis de Buffon con alguna forma de adaptacionismo. Jaques Roger (1983, p.169) lo dice con toda claridad: "lo que está totalmente ausente en el pensamiento de Buffon es la noción de adaptación". Contemporáneo de Linneo, "Buffon tuvo frente a sí a naturalistas creacionistas que gustaban de subrayar la admirable adaptación de los seres vivos a sus condiciones de vida". Pero, en lugar de buscar, como Darwin, un mecanismo capaz de explicar naturalmente esta adaptación, "Buffon prefiere negarla" (p.169). ${ }^{2}$ Así, una estructura tan conspicua como el pico del tucán no le parece a Buffon otra cosa que un trasto inútil y engorroso que desequilibra el vuelo y en nada ayuda para conseguir alimento. Para Buffon (2007a, p.1168), en todo caso, esa estructura no era más que una indicación de que en la naturaleza "todo lo que puede ser, es"; incluso si su existencia produce un ser torpe y poco viable. Y no sería, claro, ese triunfo, paulatino y siempre parcial de la materia sobre la forma que es la degeneración, lo que podría corregir esos 'desarreglos' de la naturaleza.

Decir, como Flourens (1864, p.16), que "lo que Darwin llama perfeccionamiento, Buffon lo llama degeneración" es una doble inexactitud: Buffon nunca le atribuyó a la degeneración la capacidad de optimizar las formas orgánicas en vistas a una mejor adaptación del organismo a su ambiente, ni Darwin nunca consideró que el efecto directo de factores como el clima y la alimentación pudiesen explicar el surgimiento o la optimización de estructuras adaptativas. Según éste último, al considerar a las "condiciones externas tales como clima, comida, etc. como si fuesen las únicas causas de variación", los naturalistas no conseguían explicar cosas tales como "la estructura del pájaro carpintero con sus pies, cola y lengua tan admirablemente adaptadas a capturar insectos bajo la corteza de los árboles" (Darwin, 1859, p.3). 


\section{Un programa de investigación taxonómica}

Ya antes de discutir la posibilidad de que el burro no fuese más que un 'caballo degenerado', Buffon se había valido de la idea de degeneración para caracterizar y explicar las variedades de la especie humana. En su "Historia natural del hombre", aparecida en el segundo tomo de la Historia natural, él había llegado, en efecto, a la conclusión de que "el género humano no se compone de especies esencialmente diferentes entre ellas"; y que "sólo ha existido originariamente una única especie de hombre que, habiéndose multiplicado y dispersado sobre toda la superficie de la Tierra, sufrió diferentes cambios por la influencia del clima, por la diferencia de alimentación, por la manera de vivir, por las enfermedades epidémicas, y también por la mezcla variada al infinito de individuos más o menos semejantes" (Buffon, 1749b, p.529). Pero, en esas mismas páginas, Buffon ya había dicho que esos efectos del clima y la alimentación son todavía más nítidos e intensos en los animales ${ }^{3}$; y fue también en base a ese contraste que en 1766 introdujo el tema de la degeneración de los animales.

En éstos, dice entonces Buffon (1766, p.316), los efectos que el clima y la alimentación tienen sobre su constitución son, en general, mayores que en el hombre porque, al estar más directamente expuestos a las intemperies y al injerir sus alimentos sin ninguna preparación, esos factores los afectan con mayor intensidad; y es por esa misma razón que en ellos tampoco se verifica esa flexibilidad, esa capacidad de prosperar en las más diversas regiones que caracterizan a los seres humanos. Así, "en vez de difundirse o dispersarse como el hombre", los animales "permanecen mayormente concentrados en los lugares que más le convienen" (p.346). Pero, cuando "por las revoluciones del globo o por la fuerza del hombre se han visto obligados a abandonar su tierra natal", y forzados a vivir en climas y suelos ajenos a los de su patria natural, "su naturaleza sufrió alteraciones tan grandes y profundas que ella no resulta reconocible a primera vista, y para determinarla es preciso apelar a la inspección más atenta, e incluso a experiencias y a la analogía" (p.316317). O dicho de otro modo: el hombre, por medio de la técnica y la cultura, por pobres que a veces sean, puede imponerse en toda la Tierra sin necesidad de cambiar drásticamente su constitución. Esos recursos neutralizan o moderan los efectos de las intemperies; y eso nos permite reconocer la identidad y la unidad del género humano de un modo casi inmediato. Cosa que muchas veces no ocurre con los animales: arrancados de su patria natural, éstos sufren alteraciones tan sensibles que nos cuesta reconocer su parentesco con aquellos que allí se quedaron o con aquellos que emigraron hacía otras regiones de climas también diferentes. Descubrir y reconstruir esas familias distanciadas por los avatares de la naturaleza, o por los efectos de la domesticación, es todo un programa de investigación taxonómica; y es a darnos sus primerísimas - e hipotéticas - conclusiones que Buffon consagra las páginas que aquí estamos comentando. Es decir, este escrito de Buffon se orienta, sobre todo, a individualizar y a reconstruir familias de animales producidas a partir de la degeneración de una especie originaria.

Bajo esa perspectiva, las especies integrantes de un mismo género debían ser consideradas como derivaciones de una única cepa (souche) que, en algunos casos, podía ser individualizada comparando esas especies entre sí (Buffon, 1766, p.335). Tal el caso, por ejemplo, del caballo, la cebra y el asno. Según Buffon (p.335), estas especies integrarían un mismo 
género del cual "el caballo es la cepa o el tronco principal" y "la cebra y el asno serían las ramas laterales"; y esto es lo mismo que reconocer aquello que había sido negado en 1753: el asno, al fin y al cabo, no sería otra cosa que un 'caballo degenerado'. Pero es importante remarcar que, al establecer esas conexiones de mayor o proximidad al interior de un mismo género, Buffon no sólo presta atención a las semejanzas morfológicas: para él, el criterio más importante para determinar la proximidad de dos especies es su capacidad de producir híbridos fértiles; y esto es muy importante para entender la propia noción de género presupuesta en esos análisis. Ésta, como lo subrayó Roger, no está lejos de aquel concepto biológico de especie enunciado en el segundo volumen de la Historia natural (Roger, 1989, p.426; Aréchiga, 1999, p.4; Hoquet, 2007, p.114). Allí Buffon (1749a, p.10-11) nos dice que para reconocer una especie y distinguirla de las otras se debe considerar como siendo de la misma especie a aquellos individuos que, "por la copulación", se perpetúan y conservan la similitud de esa especie, y como de especies diferentes a aquellos que, "por los mismos medios, no pueden producir nada juntos". Pero, en la medida en que Buffon fue perdiendo confianza en la definitiva esterilidad de los híbridos producidos por el cruzamiento de algunas especies (Buffon, 1766, p.342-343, 1770, p.XXI-XXII), que él llamaba, en general, mulets, esa definición biológica de especie fue transformándose en una definición biológica de género según la cual dos especies pueden considerarse como parte de un mismo género en la medida en que entre ellas exista alguna posibilidad, aunque sea mediata o remota, de cruzamiento (Flourens, 1864, p.83-84 y Roger, 1993, p.571-572; Schmitt, 2006, p.97).

Tal seria el caso, por ejemplo, de lo que ocurre con el género de los cánidos. Buffon (1766, p.351-353) concede que, tal vez con la excepción del zorro y del isatis, casi ninguna de las especies salvajes de ese género consiga cruzarse con las otras; pero, así mismo, las sospechas de que el perro podría hacerlo con todas ellas, le resultan suficiente para concluir que las mismas comparten un ancestro común. Es decir, no es necesario que todas las especies $a, b, c$ y $d$ de un género $Y$ sean capaces de cruzamientos fértiles: aunque $a$ no pueda hacerlo ni con $c$ ni con $d$, y $b$ no pueda hacerlo con $c$, basta que esto sea posible en los cruzamientos $a \leftrightarrow, b \leftrightarrow$ y $c \leftrightarrow$ para que se pueda concluir que todas ellas son formas degeneradas, más o menos lejanas, de una misma cepa originaria. Pero, aunque un experimento exitoso de cruzamiento sería siempre el test crucial para establecer la pertenencia a un género, Buffon parece persuadido de que el fracaso en esas tentativas no puede usarse para excluir o descartar tal pertenencia. El experimento de cruzamiento, diríamos hoy, nunca resulta en falsos positivos, pero puede producir falsos negativos.

Como lo muestra en su análisis de las causas que conspiran contra la fertilidad de las mulas, siempre se puede pensar que, en ciertas circunstancias muy especiales, los cruzamientos mula-asno o mula-caballo podrían ser fecundos (Buffon, 1766, p.343 y ss.); y ese sería argumento suficiente para mostrar que se trata de especies congéneres (Buffon, 1766, p.337338). Por eso, dada las dificultades planteadas por esos experimentos, los recursos más efectivos para la demarcación de los géneros continúan siendo el análisis y la comparación anatómica; y es en base a ese procedimiento que Buffon (p.360-363) consigue identificar y distinguir 25 géneros o familias de mamíferos, remitiendo esos 25 géneros a otras tantas cepas originarias: 15 de las cuales serían privativas del Viejo Continente, o comunes a los dos continentes, y diez cuyas variantes sólo se encontrarían en el Nuevo Mundo (Rostand, 
1958, p.603; Roger, 1989, p.435; Mazliak, 2006, p.227). Aunque una de ellas, la de los tigres d'Amérique, será finalmente adscripta al mismo género de la pantera y otros felinos menores del Viejo Continente (Buffon, 1766, p.363, 369). Este último grupo, sin embargo, no contiene al león y al tigre. Para Buffon (p.335, 356), ambos constituyen sendos ejemplos de un grupo muy particular de "especies aisladas, que, como la del hombre, constituyen, al mismo tiempo, especie y género". Las mismas "forman géneros o especies simples que sólo se propagan en línea directa y no presentan ramas laterales" (p.335); y por eso, siendo únicas en su género, estas especies, entre las que también se cuentan el elefante, el hipopótamo, el rinoceronte y la jirafa, tampoco pueden ser consideradas como variantes de una cepa originaria: ellas son, en todo caso, su propia cepa (Roger, 1989, p.434; Blanckaert, 1994, p.62). De todos modos, y más allá de las razones que Buffon tenía para distinguir ese conjunto de especies nobles inmunes a la degeneración, lo cierto es que si él hubiese colocado al tigre y al león a la cabeza de los carnívoros con garras; y finalmente, por alguna razón, hubiese hecho algo semejante con todas esas especies aisladas, su transformismo seguiría siendo igualmente limitado por el hecho de no reconocer ninguna vinculación genealógica entre los diferentes géneros o familias (Roger, 1983, p.165).

La cepa fundadora de cada género era para Buffon (1766, p.371) totalmente independiente en su origen de la cepa fundadora de cualquier otro género; y su referencia al hecho de que todos los animales habrían sido creados en el Viejo Continente puede darle la razón a Armand De Quatrefages (1892, p.37) cuando decía que, en "De la degeneración...", Buffon "admite la creación directa de tipos que devienen la cepa de un género o de una familia", sin jamás hacer "la menor alusión a la posibilidad de pasaje de un tipo al otro". Y, aun cuando en Las épocas de la naturaleza este creacionismo sea sustituido por el esbozo de una explicación física del origen de la vida, Buffon continuará suponiendo esa independencia genealógica de cada uno de los géneros distinguidos en "De la degeneración de los animales".

\section{Buffon y el origen de la vida}

En esa, como dice Roger (1983, p.165), "mezcla desconcertante, al menos para nosotros, de arcaísmo y modernidad" que es la teoría sobre el origen de la vida formulada en 1778, Buffon postula que "la vida apareció espontáneamente, sin ninguna intervención del Creador" (Roger, 1988, p.LXVIII). Pero, lejos de proponer que las primeras formas de vida eran seres rudimentarios o simples que luego evolucionarían hacia formas más complejas, lo que esa teoría afirma es que los organismos entonces surgidos eran tan complejos como los actuales e incluso mayores que ellos (Rostand, 1985, p.48). Esto, es cierto, puede resultarnos desconcertante; pero es perfectamente coherente con la capacidad o potencia de generar vida que Buffon le había atribuido a la naturaleza en el segundo tomo de la Historia natural. La naturaleza, nos dice allí, parece "tender mucho más a la vida que a la muerte, parece que ella procura organizar los cuerpos tanto cuanto es posible" (Buffon, 1749a, p.37); y puede decirse, incluso, que "lo viviente es lo que le cuesta menos a la Naturaleza" (p.40). "La multiplicación de los gérmenes, que puede aumentar casi al infinito, ... es una prueba de esto" (p.37); y por eso: 
Se podría decir con cierto fundamento, que si la materia no está toda organizada, es porque los seres organizados se destruyen los unos a los otros; pues podemos aumentar, casi cuanto lo queramos, la cantidad de seres vivos y vegetales, y no podemos aumentar la cantidad de piedras o de otras materias brutas; esto parece indicar que la obra más ordinaria de la Naturaleza es la producción de lo orgánico, que ésa es su acción más familiar, y que, a ese respecto, su poder es ilimitado (p.37).

Lo único que, en todo caso, podría limitar ese poder es:

La resistencia de las materias, que al no ser todas ellas de la especie que sería preciso que ellas fuesen para ser susceptibles de tal organización, no se convierten en substancias orgánicas, y esto nos prueba que la Naturaleza no tiende a hacer lo bruto sino lo orgánico, y que cuando ella no llega a ese resultado, es sólo porque existen inconvenientes que se le oponen. Parece, así, que su principal designio es, con efecto, el de producir de cuerpos organizados, y de producirlos tanto cuanto le es posible (p.38-39).

Claro, en 1749, Buffon se estaba refiriendo explícitamente a la reproducción y no al origen de la vida. Pero, si es cierto que "lo vivo y lo animado, en lugar de ser un grado metafísico de los seres, es una propiedad física de la materia" (Buffon, 1749a, p.17), si "lo orgánico es la obra más ordinaria de la naturaleza", y si además también puede decirse que "la división general que se debería hacer de la materia es entre materia viviente y materia muerta, y no entre materia organizada y materia bruta" (p.40); entonces nada tiene de sorprendente que, en determinadas condiciones, y estando disponibles los recursos necesarios, la naturaleza sea capaz de engendrar seres simples o complejos que antes no existían. Esto sólo puede parecernos difícil si insistimos en establecer un hiato profundo y casi infranqueable entre lo vivo y lo no-vivo; pero, si, a la manera de Buffon (p.40), pensamos que "lo bruto no es otra cosa que lo muerto", podríamos concebir que, en ciertas condiciones físicas particulares, la naturaleza pueda producir esas pequeñas partículas de materia viviente y que estas puedan, a su vez, ensamblarse en cuerpos de diferentes grados de complejidad (Mazliak, 2006, p.244).

$\mathrm{Y}$ esas eran, en efecto, las condiciones que existían en la tierra aun joven y plena de potencia en la que surgieron esas 'moléculas orgánicas' que, al decir de Buffon (1988, p.115), se habrían combinado de forma inmediata y espontánea, por el simple juego de las leyes de la materia, para dar nacimiento a los seres vivos (Roger, 1988, p.LXVIII). Se trató, inicialmente, de seres mayores que los actuales; y eso lo atestiguarían los restos fósiles de huesos de cuadrúpedos y de conchas cuyas dimensiones superan a las de cualquier especie aun existente. "La Naturaleza estaba entonces en su primera fuerza, y trabajaba la materia orgánica y viviente con un poder más activo, en una temperatura más cálida"; y "esa materia orgánica estaba más dividida, menos combinada con otras materias, pudiéndose reunir y combinar, ella misma, en masas mayores" (Buffon, 1988, p.98-99). Esto, concluye Buffon (p.99), "es suficiente para explicar todas las producciones gigantescas que parecen haber sido frecuentes en esas primeras edades del mundo".

En realidad, Buffon no tenía por qué pensar que los primeras formas de vida hayan sido análogas a esos minúsculos seres animados que, según él también concedía, hoy suelen formarse cuando la materia orgánica se acumula en circunstancias que no permiten su inmediata asimilación por un ser vivo ya constituido (Buffon, 1749a, p.423-424). Buffon (p.320) aceptaba, en efecto, la generación espontánea de formas de vida tan simples que 
tal vez no merecían ser llamados ni de animales ni de plantas (Flourens, 1850, p.74; Rostand, 1943, p.38; Roe, 1992, p.446; Mazliak, 2006, p.235); pero ese fenómeno, que para él era una prueba más de la fuerte propensión a organizarse que caracteriza a la materia orgánica, era algo cuya ocurrencia sólo debía esperarse en una situación como la actual, es decir, en un contexto en el cual la mayor parte de esa materia orgánica estaba ya integrada en los cuerpos de otros vivientes. En tiempos remotos, en cambio, cuando la Naturaleza estaba en la plenitud de sus fuerzas y había superabundancia de materia orgánica disponible para combinarse en grandes masas, ese fenómeno sólo podía ser algo marginal: lo que en esas circunstancias era de esperarse era que, movida por su propio ímpetu a la aglomeración, esa materia generase, desde el inicio, grandes formas vivas sin necesidad de pasar por etapas intermediarias de menor tamaño y complejidad. Allí, lo grandioso y lo portentoso serían siempre algo más probable que lo exiguo y lo miserable (Cohen, 2004, p.162).

No pensemos, por otro lado, que Buffon haya considerado que esos fenómenos de organización molecular fuesen algo fortuito. Para él, como lo explica Peter Bowler (1994, p.135), las especies originarias estaban incorporadas "a la trama misma de la naturaleza" y representaban "una organización potencialmente estable de las partículas materiales que alcanzarían a manifestarse físicamente siempre que fuesen adecuadas las condiciones físicas" (Buffon, 1764, p.IV). Por eso, decía Buffon (1775, p.509), "en todos los lugares en donde la temperatura es la misma, encontramos no solamente las mismas especies de plantas, las mismas especies de insectos, las mismas especies de reptiles, sin haberlos llevado allí, sino que también encontramos las mismas especies de peces, las mismas especies de cuadrúpedos, las mismas especies de aves, sin que ellas hayan debido llegar hasta allí"; y esa estricta correlación entre temperatura y formas de la organización vital le permite incluso conjeturar que, si en otros planetas del sistema solar se diesen las mismas condiciones de temperatura en las que se originaron las especies terrestres, en ellos veríamos surgir no sólo la vida, sino los mismos animales que pueblan nuestro planeta (p.509).

Podríamos así decir que, para Buffon, tanto las especies 'mayores' o 'nobles' como las cepas originarias de las familias afectadas por la degeneración constituyen clases naturales que se materializan cada vez que se dan las condiciones físicas adecuadas para que las moléculas orgánicas se aglomeren de una determinada manera; y es en este sentido que puede afirmarse que las especies son êtres perpétuels, tan permanentes como la propia naturaleza (Buffon, 1765, p.I), sin que eso implique renunciar a un cierto transformismo.

Las especies, en efecto, son formas posibles de la organización que, como acabo de decir, se actualizan cuando las condiciones físicas así lo permiten; pero una vez pasado ese instante en que la temperatura y la disponibilidad de las moléculas orgánicas permiten el surgimiento de individuos concretos de un determinado tipo, la forma de éstos queda sometida a la influencia de diferentes circunstancias que la van modificando. Las condiciones de temperatura se van alejando del punto óptimo que posibilitó esa aglomeración particular de la materia orgánica; y este desvío, conjugado con la lenta pero minuciosa influencia de la dieta y del modo de vida, va produciendo cambios, más o menos sensibles, que, tras varias generaciones, pueden llegar desdibujar los contornos de los prototipos originarios menos estables. Los otros, los más 'nobles', sufren menos esas influencias y tienden a permanecer casi inalterados. 
Inicialmente, esas condiciones propicias al surgimiento de las formas orgánicas sólo podían darse en las regiones más septentrionales del globo que fueron las primeras en enfriarse: allí la temperatura, aun siendo en ese entonces muy superior a la que actualmente encontramos en el Ecuador, era lo suficientemente baja como para permitir alguna forma de vida (Buffon, 1988, p.165); y es por eso que es allí en donde pueden encontrarse los restos de esos animales gigantes hoy ya extintos (p.118, 171), cuyo tamaño, insisto, nos habla "de la gran fuerza de la Naturaleza en esos primeros tiempos" (p.171). Los mismos, sin embargo, habrían perecido por no resistir el progresivo enfriamiento de la tierra (Roger, 1983, p.168, 1989, p.545); y de la liberación de las moléculas orgánicas producida por esa mortandad, habría surgido, en esa misma región del globo, una segunda generación de seres entre los cuales se contarían todas las especies nobles y todas las cepas originarias de los géneros de cuadrúpedos que hoy ocupan la región meridional del viejo mundo (Buffon, 1988, p.169). Entre estos, sin embargo, había algunas especies, como el hipopótamo y el elefante, que eran semejantes en forma, aunque menores en tamaño, a las especies de la primera andanada de vida; y esto es fácilmente comprensible: las leyes que regulan la organización de las moléculas orgánicas son siempre las mismas, y en condiciones semejantes producen seres semejantes. Pero, como la temperatura ya era un poco menor, el tamaño de los mismos también tendía a ser menor. Para Buffon, la semejanza morfológica entre dos tipos de animales no tiene por qué ser siempre y necesariamente explicada en virtud de algún vínculo genealógico: bajo condiciones físicas semejantes, la naturaleza produce seres semejantes sin que exista entre ellos ningún nexo de filiación (Roger, 1988, p.LXX, 1989, p.546, 1993, p.580).

Los restos de mamuts encontrados en la Siberia y en Canadá, que Buffon, en algunos casos, confunde con los de elefantes actuales, serían un testimonio de esa segunda etapa de la historia de la vida. Pero digo 'en algunos casos', porque ya en "Animales comunes a los dos continentes", Buffon (1761, p.126) se había referido al "prodigioso mamut ..., por lo menos seis veces mayor que el elefante más corpulento"; y, además de eso, en ciertos pasajes de Las épocas..., él también se refiere a restos de elefantes mayores a los actuales que formarían parte de esa primera generación ya extinta de cuadrúpedos (Buffon, 1988, p.169, 171). Buffon, en realidad, sólo usa la palabra mamut para referirse a una especie extinta mayor que la del elefante actual; sólo que, como parece tener una imagen un poco exagerada del tamaño de esos animales, tiende a confundir algunas osamentas de genuinos mamuts con las de meros elefantes, tal vez sólo un poco mayores que los actuales. Esta confusión le viene, por otro lado, muy bien; porque, de ese modo, puede imaginar un periodo en el cual los elefantes actuales deambulaban por las mismas tierras septentrionales en las que antes habían vivido los, para él, verdaderos mamuts. ${ }^{4}$

Como sea, esta segunda etapa de la historia de la vida habría concluido cuando, empujada por el mismo proceso de enfriamiento de la tierra que había acabado con su predecesora, esa fauna fue abandonando las regiones septentrionales y encaminándose hacia las regiones meridionales que, al perder también temperatura, se tornaban adecuadas para ella (Buffon, 1988, p.171-173). En América, esa marcha se habría visto interrumpida por montañas demasiado altas y frías para ser franqueadas por animales de clima cálido; y éstos se habrían extinguido sin poder llegar hasta la América meridional (p.174-175). Pero, en el Viejo 
Continente, esa migración habría continuado hacia el África y el sur del Asía, regiones donde esa fauna aún persiste, compartiendo el espacio con animales menores, 'inferiores', producidos por esa misma región (p.177-178). ${ }^{5}$

Sin embargo, e independientemente de la desigual suerte que corrieron aquellos dos contingentes de animales, lo cierto es que, en las regiones septentrionales de ambos continentes, esa fuga y esa extinción masiva produjeron efectos semejantes: dejaron paso a una tercera generación de animales producida por un clima más frío y, por lo tanto, más adecuada a las bajas temperaturas. Esos animales componen la fauna actual de Europa, de Norteamérica y del Norte de Asia; y su origen simultaneo explica las semejanzas que existen entre ellas (Buffon, 1988, p.176). Ya más tarde, una tierra algo agotada y muy fatigada, habría dado origen a los animales propios de la América meridional (p.179). Esta siempre malhadada región del mundo, "dejada a sus propias fuerzas, sólo alumbró animales más débiles y mucho menores que aquellos que llegaron del Norte para poblar las regiones meridionales del Viejo Continente" (p.177). El tatú, la zarigüeya y el perezoso serían buenos ejemplos de esas producciones postreras; pero Buffon (p.178) prefiere citar al tapir: ese irrisorio 'elefante del Nuevo Mundo' que, además de no tener ni trompa ni colmillos, no es mayor que un humilde burrito.

Además de propiciar la degeneración de todas, o casi todas ${ }^{6}$, las especies que llegasen desde el norte y desde el Viejo Continente, por sí misma, la América meridional sólo había generado criaturas menores y mal entrazadas; y eso explicaría lo que ya había mostrado el análisis de la fauna del nuevo mundo desarrollado en "De la degeneración de los anímales": las especies que componían los nueve géneros de cuadrúpedos propios del Nuevo Mundo, al igual que las tres especies aisladas de allí, oriundas, serían de origen sudamericano; y, por eso, sólo alcanzaban el tamaño de los animales menos conspicuos del Viejo Mundo. Su forma, sin embargo, podía ser eventualmente semejante a la de estos últimos; porque ella respondía necesariamente a las mismas leyes universales de organización de la materia.

\section{El silogismo que no fue}

Pero, sin menoscabar la audacia y el innegable poder explicativo de las hipótesis de Buffon, lo que en ellas inevitablemente desconcierta, y en cierto modo nos defrauda, es el hecho de que todo ese despliegue de generaciones espontáneas, sucesivas e independientes, de grandes y pequeños animales, resulte una hipótesis más inmediatamente accesible que una posible radicalización del transformismo esbozado en "De la degeneración de los animales". Al fin y la cabo, Buffon ya tenía casi todas las piezas para dar ese paso. En 1753, cuando su artículo sobre el asno, había dicho, recordémoslo, que:

Si se admite una vez que hay familias en las plantas y en los animales, que el asno sea de la familia del caballo, y que él degeneró, podríamos decir igualmente que el simio es de la familia del hombre; que es un hombre degenerado; que el hombre y el simio tienen un origen común como el caballo y el asno; que cada familia, tanto entre los animales como entre los vegetales, deriva de una única cepa, e incluso que todos los animales provienen de un único animal que, con el transcurrir del tiempo, produjo, al perfeccionarse y al degenerar, todas las razas de los otros animales (Buffon, 1868, p.36). 
Y después de "De la degeneración de los animales", el antecedente de ese condicional ya estaba concedido: había, al final de cuentas, familias de plantas y de animales; y el asno, después de todo, era una forma degenerada del caballo. Sólo faltaba aceptar el consecuente y sostener, tal vez, que todos los animales derivan de un único ancestral común; cualquiera sea él y cualquiera sea su naturaleza. ¿Por qué, entonces, no explorar esa posibilidad? ¿Qué era lo que se interponía entre Buffon y esa consecuencia aparentemente casi inmediata de la evolución de sus reflexiones? No creo que hayan sido ni convicciones teológicas, ni miedo a la censura eclesiástica: si fuese por eso Buffon tampoco hubiese propuesto esas hipótesis sobre el origen de la vida a las que me acabo de referir (Roger, 1993, p.581-582). Suponer que las formas vivas se originaron espontáneamente, sin ninguna intervención del Creador, no parece menos contrario a la revelación que un transformismo radical. Pienso, por eso, que las respuestas que podemos concebir para esta cuestión deben buscarse en el interior del sistema teórico delineado por Buffon.

Ninguna de ellas, de todos modos, será muy fácil de justificar; y esto es así por la sencilla razón de que en Las épocas de la naturaleza, Buffon prácticamente no retoma ninguno de los asuntos de "De la degeneración de los animales" (Roger, 1983, p.168, 1989, p.543). "Completamente prisionero ... de la lógica de un nuevo sistema, Buffon parece olvidarse de los resultados de su reflexión anterior, pasando a nuevos problemas que él va resolver de un modo más o menos feliz" (Roger, 1989, p.544); y, entre esos 'olvidos' se destacan la propia temática de la degeneración y los ensayos de establecer relaciones de filiación entre diferentes especies (p.548). No creo, sin embargo, que del eclipse de esas temáticas se pueda concluir que, en 1778, Buffon haya renegado de aquel transformismo limitado de 1766.

Es cierto que en el Primer discurso de las épocas Buffon (1988, p.26-27) nos dice que "cuando se compara esos antiguos monumentos de la primera edad de la Naturaleza viviente con sus producciones actuales, se hace evidente que la forma constitutiva de cada animal se mantuvo la misma y sin alteración en sus principales partes: el tipo de cada especie nada cambió; el molde interior conservó su forma y en nada varió". Pero creo que es necesario reparar en los adjetivos 'constitutivo' y 'principal': ellos parecen estar ahí para indicarnos que ciertas partes accidentales o secundarias, no constitutivas, sí pudieron cambiar. Y decir eso, como lo observó ya hace mucho Jean Rostand (1932, p.55), implica preservar un espacio para la degeneración. Fenómeno que, además, el propio Buffon mencionará a continuación, retomando, incluso, la distinción entre especies mayores y especies inferiores presupuesta en sus análisis de 1766.

Buffon (1988, p.27) nos dirá, es verdad, que "los individuos de cada género representan hoy las formas de aquellos de los primeros siglos"; pero también reconocerá que esto es así "sobre todo en las especies mayores, cuyo cuño es más firme y cuya Naturaleza es más fija", porque "las especies inferiores han, como lo hemos dicho, padecido de una manera sensible todos los efectos de las diferentes causas de degeneración". Es decir: más allá de sus continuas y conocidas oscilaciones en el uso de los términos especie y género (Roger, 1989, p.426 y ss; Gayon, 1992, p.479 y ss), Buffon continúa dando por establecida su teoría de la degeneración; y hasta puede decirse que tiene que preservarla para justificar el hecho de que, aún especies mayores como el elefante y el hipopótamo fuesen hoy menores de lo que eran cuando una naturaleza más vigorosa que la actual produjo sus primeros ejemplares. 
Aunque no parezca querer volver a discutir sobre el asunto, Buffon de hecho conserva su distinción entre especies aisladas o nobles que no degeneran y especies menores que conforman géneros derivados de cepas originarias que sí han padecido, y padecen, procesos de degeneración. Aunque lo ha dejado al margen y lo ha desplazado del centro de la discusión, Buffon no renuncia a su transformismo limitado. Lo que él no puede, sin embargo, es radicalizarlo; y es por las razones de esa imposibilidad que, insisto, debemos preguntarnos.

\section{La impotencia de la degeneración}

En este sentido, lo primero que debe apuntarse es que la relativa estabilidad que Buffon (2007h, p.528) le adjudica al prototipo original de cada especie, o de cada género, no adviene del hecho de que el mismo sea considerado como una suerte de forma o arquetipo platónico ajeno a los avatares del mundo natural. Para Buffon (1765, p.VII), como vimos, ese prototipo no es otra cosa que el propio cuerpo de aquellos primeros individuos de una especie o género que, según su teoría sobre el origen de la vida de 1778, se habrían originado por esos súbitos procesos naturales de amalgamamiento de las moléculas orgánicas a los que antes me referí; $y$, si ese molde puramente natural tiende a mantenerse, es sólo porque las influencias del clima y de la alimentación son insuficientes para alterar sus perfiles de una forma demasiado drástica. Aunque el proceso de degeneración pueda ser acumulativo y progresivo, el mismo tiene un límite bastante obvio: ningún organismo puede transmitir a su descendencia cambios que no haya padecido y que no pueda soportar.

Los cambios que la degeneración puede producir en las formas vivas pueden ser, a lo sumo, una acentuación progresiva de cambios morfológicos que sobrevienen en un organismo individual sin que eso implique su propia aniquilación. Estos cambios son, por eso, bastantes limitados: los más obvios son un incremento o una disminución de peso y tamaño, la atrofia o hipertrofia de algunas estructuras anatómicas particulares, un cambio de color o de comportamiento, el mayor o menor crecimiento del pelaje y la aparición de algunas callosidades. Y, si aceptamos las hipótesis más osadas de Buffon sobre el modo en que las moléculas ingeridas pueden afectar la forma del viviente, podemos agregar a esa lista la modificación en la constitución de ciertos tejidos y el surgimiento de estructuras secundarias y accidentales como los cuernos de los ciervos (Buffon, 2007e, p.723). Nunca, por más que forcemos nuestra imaginación, podemos llegar a concebir que esos procesos puedan afectar, ni siquiera de forma insipiente, la estructura fundamental de un organismo. Esos cambios afectan estructuras preexistentes; pero no crean siquiera los rudimentos de nuevas estructuras.

Por eso, si la influencia de las condiciones de vida como la dieta, el clima y el comportamiento sólo afectan estructuras preexistentes y son incapaces de producir siquiera los rudimentos de nuevas estructuras; entonces, aun cuando esos procesos se acumulen a lo largo de innúmeras generaciones, los mismos continuarán siendo impotentes para producir cualquier innovación morfológica. La degeneración puede ser poderosa a la hora de erosionar y alterar formas preexistentes; pero, del mismo modo en que sería impotente para producir estructuras adaptativas, ella también resultaría incapaz de producir innovaciones morfo- 
lógicas. Pero, como esas innovaciones también son necesarias para tornar aceptables la desaparición, e incluso la disminución, de otras estructuras preexistentes, también podemos concluir que ese proceso de 'empobrecimiento' estructural tampoco puede ir muy lejos, aun cuando insistamos en proyectarlo a lo largo de varias generaciones.

Puede decirse, por eso, que del mismo modo en que la degeneración no puede llevarnos del infusorio o del pólipo al hombre, tampoco puede hacernos recorrer el camino inverso; y así, dado cualquier animal, o dado cualquier conjunto significativamente pequeño de animales, más o menos complejos, que pudiésemos escoger como prototipo o prototipos de todos los otros, la mera degeneración sería insuficiente para producir, a partir de él o de ellos, toda la panoplia de los seres existentes y extintos. Pero no hace falta ir tan lejos para percibir esa impotencia de la degeneración: Buffon la reconocía cuando consideraba las diferencias morfológicas existentes entre animales mucho más próximos que una pantera y un lobo; y esto lo vemos en sus cavilaciones sobre la posibilidad de tratar a las especies y géneros propios de América como si fuesen simples variantes de algunos géneros del Viejo Continente.

Es que, aun cuando sea obvio que ninguna de esas especies y géneros peculiares al Nuevo Mundo pueda cruzarse con las del Viejo Continente, entre aquéllas y algunas de éstas existen, según reconoce Buffon (1766, p.363), "relaciones remotas que parecen indicar alguna cosa de común en su formación" y que, a su vez, también nos sugieren la posibilidad de que su origen se deba "a causas de degeneración mayores y, quizá, más antiguas que todas las otras". Es decir: las semejanzas lejanas y vagas que existen entre ciertos animales de América y ciertos animales del Viejo Continente parecen invitarnos a ir un poco más allá del género en el establecimiento de relaciones de filiación y a suponer un origen común entre dos especies o géneros, aun cuando hasta la más remota, indirecta e improbable posibilidad de cruzamiento entre ellas se haya perdido irremisiblemente. Sin embargo, aunque el razonamiento a nosotros nos parezca plausible, Buffon examina y compara morfológicamente esas especies y acaba retrocediendo a su posición inicial: hay familias americanas enteras que no pueden ser consideradas como variantes degeneradas de familia europea alguna. Tal el caso, por ejemplo, de los monos del Nuevo Mundo y de las zarigüeyas. Los primeros, reconoce Buffon (p.368), se parecen mucho a los monos con cola del Viejo Mundo; pero, según él apunta, no cabría emparentarlos porque "sería muy difícil de concebir cómo" estos últimos habrían podido "tomar en América una forma de cara diferente, una cola musculosa y prensil, un ancho tabique entre las narices y otros caracteres, tanto específicos cuanto genéricos" que caracterizan a los monos del Nuevo Mundo. Y algo semejante se puede decir de las zarigüeyas y de los lémures: en cierto modo, parece pensar Buffon (p.368-369), estos géneros podrían ser emparentados; pero sus diferencias son demasiado grandes para permitirlo. No podríamos llegar a "suponer que ellos provengan los unos de los otros sin suponer, al mismo tiempo, que la degeneración puede producir efectos iguales a los de una Naturaleza nueva"; y, para convencernos de esa imposibilidad, Buffon repasa ciertas características de las zarigüeyas cuyo origen no puede ser explicado por degeneración de las características de los lémures: 
La mayoría de esos cuadrumanos de América [las zarigüeyas] poseen un saco bajo el vientre; la mayoría tienen diez dientes en el maxilar superior y otros diez en el inferior; la mayoría tienen la cola prensil, mientras que los lémures tienen la cola laxa, carecen de sacos sobre el vientre y sólo tienen cuatro dientes incisivos en el maxilar superior, y seis en el inferior: así, aun cuando estos animales tengan las manos y los dedos conformados de la misma manera, y que se asemejen también por el largo del hocico; sus especies y sus géneros, son tan diferentes, tan alejados, que no se puede imaginar que deriven los unos de los otros, ni que disparidades tan grandes y generales hayan sido jamás producidas por la degeneración (p.369).

Claro, la aproximación entre lémures y zarigüeyas nos puede parecer un tanto arbitraria; y la presuposición de que la degeneración debe ser siempre desde los animales del Viejo Continente hacia los del Nuevo, pero nunca a la inversa (Buffon, 1766, p.371), puede hacernos sonreir. Pero, aun así, el hecho de que Buffon niegue que las diferencias entre ambas familias puedan ser explicadas por degeneración nos muestra que él reconocía que ésta era una fuerza transformadora harto limitada. Ella, por las mismas razones que le impiden producir una llama a partir de un camello, o un tapir a partir de un elefante, tampoco puede producir un órgano nuevo como el marsupio, no puede alterar un sistema de dentición y no puede producir una cola prensil; y si no puede hacer eso, es claro que tampoco puede llevarnos del pólipo al pulpo, o de éste a aquél, por más tiempo y generaciones que le demos para cumplir el servicio.

Por eso, cuando llega al examen de los cuatíes, los armadillos y los perezosos, Buffon (1766, p.372) desiste de aproximarlos a cualquier género del Viejo Mundo y concluye que no es posible "atribuir a los efectos de la degeneración las prodigiosas diferencias que encontramos en su naturaleza de la cual ningún otro animal nos puede dar ni el modelo ni la idea". Es más, según Buffon (p.371), hasta es improbable que la degeneración haya podido transformar las placas que protegen al pangolín asiático en los pelos que cubren a los osos hormigueros, sus posibles primos de la América meridional, y por eso deja abierta la cuestión de si estos son o no una forma degenerada de aquellos. Buffon, podríamos decir, acabó llegando a la misma conclusión a la que había llegado José de Acosta (2003, p.283) en su Historia natural y moral de las Indias, de 1591: "quien por esta vía de poner sólo diferencias accidentales pretendiere salvar la propagación de los animales de Indias y reducirlos a los de Europa, tomará carga pesada, que mal podrá salir con ella. Porque si hemos de juzgar las especies de los animales por sus propiedades, son tan diversas que quererlas reducir a especies conocidas de Europa, será llamar al huevo castaña". Sólo que donde Acosta dice 'Europa', Buffon decía 'Viejo Mundo'; y donde aquel decía 'diferencias accidentales'; este decía 'degeneración'.

Esto puede explicar el origen de los felinos americanos a partir de los del Viejo Mundo, porque esas transformaciones sólo exigen alteraciones de miembros y órganos que se preservan en toda la familia, pero no puede ir mucho más allá de eso: hay diferencias entre los géneros que ella nunca podría producir (Buffon, 1766, p.373). Pero no porque exista un tope de esencias inmutables que lo impida, sino por virtud de la propia limitación que la degeneración padece en cuanto que agente transformador. Ella sólo modela y remodela lo que existe; pero no puede producir nada de nuevo; y es por eso que para explicar las peculiaridades de los mamíferos sudamericanos era más razonable apelar a un origen 
independiente, producido por una naturaleza algo fatigada y agotada, que a los efectos del clima y la alimentación. Estos factores nunca habrían podido producir esas formas extravagantes que caracterizan a las zarigüeyas, a los armadillos, o a los simples cuatíes.

No es por acaso que para superar ese límite que impidió la radicalización del transformismo buffoniano, Lamarck $(1802$, p.16) haya tenido que postular una tendencia al incremento de la complejidad que regía la constitución del embrión y que se continuaba y se profundizaba en la sucesión de las generaciones. Esa fuerza impulsaba el establecimiento de cada nuevo sistema de órganos; y las circunstancias sólo contribuían a la modificación de esas estructuras que ellas, por otra parte, eran impotentes para producir (Lamarck, 1820, p.141). Es decir, Lamarck, como después Darwin, pudo concebir un proceso de transformación capaz de generar por sí mismo toda la variedad de seres vivientes porque su teoría postuló un factor de innovación ajeno a la simple trasmisión de las modificaciones que un organismo sufría en virtud de sus condiciones de vida. Buffon no llegó a vislumbrar nada análogo; y por eso prefirió confiar el origen de sus especies fundamentales a esos súbitos procesos de aglomeración de las moléculas orgánicas.

Buffon, en suma, fue coherente con las reglas de su propio sistema y no le pidió a la degeneración lo que, desde 1766, ya sabía que no le podía pedir. Su transformismo podía ser limitado, pero su comprensión de la complejidad del problema que estaba enfrentando, y del alcance de los instrumentos con que contaba para abordarlo, ciertamente no lo era. Por eso, lejos de ser vistas como claudicación, sus posiciones de 1778 deben ser consideradas como la más coherente y audaz profundización en dirección a una concepción materialista de la historia de la vida de la que podían ser objeto sus tesis de 1766.

\section{NOTAS}

${ }^{1}$ En esta y en las demás citas de texto en otros idiomas, la traducción es libre.

2 Al respecto, ver también: Rostand, 1985, p.51, Giordan, 1987, p.239, Bowler, 1998, p.133, Shanahan, 2004, p.96 y Mazliak, 2006, p.230.

${ }^{3}$ Ver también Buffon, $2007 \mathrm{~h}$, p.531 y 1761, p.2.

${ }^{4}$ En realidad, fue sólo a partir de la memoria leída por Cuvier en 1796 que la relación entre los elefantes fósiles y los actuales comenzó a ser aclarada (Cohen, 2004, p.174 y ss). En ese trabajo, además de establecer que los elefantes de India y África pertenecían a dos especies diferentes, Cuvier (1798, p.21) también mostró que las osamentas de elefantes fósiles hasta ese momento conocidas pertenecían también a dos especies diferentes: el Elephas mammonteus y el Elephas americanus .

${ }^{5}$ Como a muchos contemporáneos nuestros les ocurre con las producciones culturales, Buffon no dudaba de que "todo lo que hay de colosal y de grande en la Naturaleza, se formó en las tierras del Norte"; y daba por descontado que, si las tierras del Ecuador "produjeron algunos animales, ellos son especies inferiores, mucho más pequeñas" que aquellas producidas en el Norte (Buffon, 1988, p.178).

${ }^{6}$ En "De la degeneración..." Buffon (1766, p.370-371) abrió, en efecto, una excepción para el zorrino, cuya pestilencia se habría 'perfeccionado' en el Nuevo Mundo. 


\section{REFERENCIAS}

ARÉCHIGA, Violeta.

El concepto de degeneración en Buffon. In: Gutiérrez Lombardo, Raúl Martínez Contreras, Jorge; Vera Cortés, José (Org). Estudios en historia y filosofía de la biología, 1. México: Centro Vicente Lombardo Toledano. p.1-20. 1999.

BLANCKAERT, Claude.

Le temps, grand ouvrier de la nature. In: Buffon: du Grand Livre de la Nature à la Grande Galerie. Paris: Les Cahiers de Science \& Vie. p.58-73. 1994.

BOWLER, Peter

Historia Fontana de las ciencias ambientales. México: Fondo de Cultura Económica. 1994.

BUFFON, Georges.

Les toucans (du tome VI de la "Histoire naturelle des oiseaux"). In: Euvres de Buffon. Paris: Gallimard. p.1167-1173. 1.ed., 1780. 2007a.

BUFFON, Georges.

Le buffle, le bonasus, l'auroch, le bison et le zébu (du tome XI de la "Histoire naturelle générale et particulière"). In: (Euvres de Buffon. Paris: Gallimard. p.952-983. 1.ed., 1764. 2007b.

BUFFON, Georges.

Les animaux carnassiers (du tome VII de la "Histoire naturelle générale et particulière"). In: Euvres de Buffon. Paris: Gallimard. p.747-767. 1.ed., 1758. 2007c.

BUFFON, Georges.

Le loup (du tome VII de la "Histoire naturelle générale et particulière"). In: Euvres de Buffon. Paris: Gallimard. p.768-776. 1.ed., 1758. 2007d.

BUFFON, Georges.

Le cerf (du tome VI de la "Histoire naturelle générale et particulière"). In: (Euvres de Buffon. Paris: Gallimard. p.708-733. 1.ed., 1756. 2007e.

BUFFON, Georges.

Les animaux sauvages (du tome VI de la

"Histoire naturelle générale et particulière"). In: CEuvres de Buffon. Paris: Gallimard. p.703-707. 1.ed., 1756. 2007f.

BUFFON, Georges.

Le boeuf (du tome IV de la "Histoire naturelle générale et particulière"). In: (Euvres de Buffon. Paris: Gallimard. p.571-593. 1.ed., 1753. 2007g.

BUFFON, Georges.

Le cheval (du tome IV de la "Histoire naturelle générale et particulière"). In: (Euvres de Buffon. Paris: Gallimard. p.503-553. 1.ed., 1753. 2007h.

BUFFON, Georges.

Les époques de la nature. Ed. critique, Jacques
Roger. Paris: Muséum National de Histoire Naturelle. 1.ed., 1778. 1988.

BUFFON, Georges.

L'âne (du tome IV de la "Histoire naturelle générale et particulière"). In: (Euvres de Buffon. v.3. Mises en ordre et annotées par Jules Pizzetta. Paris: Parent-Desbarres. p.35-43. 1.ed., 1753. 1868.

BUFFON, Georges.

Histoire naturelle générale et particulière: deuxième supplément. Paris: L'Imprimerie Royale. 1775.

BUFFON, Georges.

Histoire naturelle des oiseaux. t.1. Paris: L'Imprimerie Royale. 1770.

BUFFON, Georges.

Histoire naturelle générale et particulière. t.14. Paris: L'Imprimerie Royale. 1766.

BUFFON, Georges.

Histoire naturelle générale et particulière. t.13. Paris: L'Imprimerie Royale. 1765.

BUFFON, Georges.

Histoire naturelle générale et particulière. t.12. Paris: L'Imprimerie Royale. 1764.

BUFFON, Georges.

Histoire naturelle générale et particulière. t.9. Paris: L'Imprimerie Royale. 1761.

BUFFON, Georges.

Histoire naturelle générale et particulière. t.2. Paris: L'Imprimerie Royale. 1749a.

BUFFON, Georges.

Histoire naturelle générale et particulière. t.3. Paris: L'Imprimerie Royal. 1749b.

CAPONI, Sandra.

Sobre la aclimatación: Boudin y la geografía médica. História, Ciências, Saúde - Manguinhos, Rio de Janeiro, v.14, n.1, p.13-38. 2007.

COHEN, Claudine.

Le destin du mammouth. Paris: Seuil. 2004.

CUVIER, Georges.

Mémoire sur les espèces d'éléphants vivantes et fossiles. Mémoires de L'Institut National des Sciences et Arts, Paris, v.2, p.1-26. 1798.

DARWIN, Charles.

On the origin of species. London: Murray. 1859.

DE ACOSTA, José.

Historia natural y moral de las Indias. Madrid:

Dastín. 1.ed., 1591. 2004. 
DE QUATREFAGES, Armand.

Darwin et ses précurseurs français. Paris: Felix Alcan. 1892.

FLOURENS, Pierre.

Examen du livre de M. Darwin sur l'origine des espèces. Paris: Garnier, 1864.

FLOURENS, Pierre.

Histoire des travaux et des idées de Buffon. Paris: Hachette, 1850.

GAYON, Jean.

La individualité de la espèce: une thèse transformiste?. In: Gayon, Jean (Org.). Buffon 88. Paris: Vrin. p.475-490. 1992.

GAYON, Jean.

Hérédité des caractères acquis. In: Corsi, Pietro et al. Lamarck, philosophe de la nature. Paris: Presses Universitaires de France. p.105-163. 2006.

GEOFFROY SAINT HILAIRE, Etienne. Principes de philosophie zoologique. In: Le Guyader, Hervé. Geoffroy Saint-Hilaire. Paris: Belin. p.129-237. 1.ed., 1830. 1998.

GEOFFROY SAINT HILAIRE, Isidore. Acclimatation et domestication des animaux utiles. Paris: Librairie Agricole de la Maison Rustique. 1861.

GEOFFROY SAINT HILAIRE, Isidore. Recherches zoologiques et physiologiques sur les variations de la taille chez les animaux et dans les races humaines. In: Mémoires présentés par divers savants a l'Académie Royale des Sciences de l'Institut de France. v.3. Paris : Imprimerie Royale. p.503-572. 1832.

GIORDAN, André.

Histoire de la biologie II. Paris: Lavoisier. 1987.

HOQUET, Thierry.

Buffon/Linné. Paris: Dunod. 2007.

LAMARCK, Jean.

Système analytique des connaissances positives de l’homme. Paris: Belin. 1820.

LAMARCK, Jean.

Recherches sur l'organisation des corps vivants.

Paris: Maillard. 1802.
MAZLIAK, Paul.

La biologie au siècle des Lumières. Paris: VuibertAdapt. 2006.

OSBORNE, Michael.

Nature, the exotic, and the science of French colonialism. Indianapolis: Indiana University Press. 1994.

ROE, Shirley.

Buffon and Needham. In: Gayon, Jean (Org.). Buffon 88. Paris: Vrin. p.439-450. 1992.

ROGER, Jacques.

Les sciences de la vie dans la pensée française au XVIII siècle. Paris: A. Michel. 1993.

ROGER, Jacques.

Buffon. Paris: Fayard. 1989.

ROGER, Jacques.

Introduction. In: Roger, Jacques. Buffon: les époques de la nature. Paris: Muséum National de Histoire Naturelle. 1988.

ROGER, Jacques.

Buffon et le transformisme. In: Biezunski,

Michel (Ed.). La recherche en histoire des sciences. Paris: Seuil. p.149-172. 1983.

ROSTAND, Jean.

Introducción a la historia de la biología. Barcelona: Planeta. 1985.

ROSTAND, Jean.

Les grandes problèmes de la biologie. In: Taton, René (Org.). La science moderne: de 1450 a 1800. Paris: Presses Univeritaires de France. p.597-618. 1958.

ROSTAND, Jean.

La genèse de la vie: histoire des idées sur la génération spontanée. Paris: Hachette. 1943.

ROSTAND, Jean.

L'évolution des espèces: histoire des idées transformistes. Paris: Hachette. 1932.

SHANAHAN, Timothy.

The evolution of darwinism. Cambridge: Cambridge University Press. 2004.

SCHMITT, Stephan.

Aux origines de la biologie moderne: l'anatomie comparée d'Aristote à la théorie de l'évolution. Paris: Belin. 2006. 